\title{
A global model for residential energy use: Uncertainty in calibration to regional data
}

\author{
Bas van Ruijven $^{\mathrm{a}, *}$, Bert de Vries ${ }^{\mathrm{a}, \mathrm{b}, 2}$, Detlef P. van Vuuren ${ }^{\mathrm{a}, 1}$, Jeroen P. van der Sluijs ${ }^{\mathrm{b}, 3}$ \\ ${ }^{a}$ Netherlands Environment Assessment Agency (PBL), PO Box 1, 3720 BA Bilthoven, The Netherlands \\ ${ }^{\mathrm{b}}$ Utrecht University, Copernicus Institute for Sustainable Development and Innovation, Department of Science, Technology and Society, \\ Heidelberglaan 2, 3584 CS Utrecht, The Netherlands
}

\section{A R T I C L E I N F O}

\section{Article history:}

Received 12 February 2009

Received in revised form 16 July 2009

Accepted 19 September 2009

Available online 22 October 2009

\section{Keywords:}

Uncertainty

Model calibration

Residential energy use

\begin{abstract}
A B S T R A C T
Uncertainties in energy demand modelling allow for the development of different models, but also leave room for different calibrations of a single model. We apply an automated model calibration procedure to analyse calibration uncertainty of residential sector energy use modelling in the TIMER 2.0 global energy model. This model simulates energy use on the basis of changes in useful energy intensity, technology development (AEEI) and price responses (PIEEI). We find that different implementations of these factors yield behavioural model results. Model calibration uncertainty is identified as influential source for variation in future projections: amounting $30 \%$ to $100 \%$ around the best estimate. Energy modellers should systematically account for this and communicate calibration uncertainty ranges.
\end{abstract}

(c) 2009 Elsevier Ltd. All rights reserved.

\section{Introduction}

Developments of the energy system play a key role in economic development and environmental problems at different scales. This includes issues like access to modern energy, securing energy supply and environmental problems, such as air pollution and climate change. It is therefore important to explore different potential development paths of the energy system. However, at least two factors complicate projections of future energy use: (1) the energy system is determined by complex interactions of a wide range of drivers and (2) there is a lack of empirical data. This lack of information complicates the development and calibration of models, especially for developing regions - and allows for multiple interpretations of the same phenomena. Despite these difficulties, a wide range of models has been developed to explore trends in the energy system at global [1-5], regional [6-8] and national scales $[6,7,9,10]$. These models are partly developed from different scientific paradigms and modelling traditions. Such paradigms may lead to different interpretations of the past and different

\footnotetext{
* Corresponding author. Tel.: +31 30274 3043; fax: +31 302744464 .

E-mail addresses: bas.vanruijven@pbl.nl (B. van Ruijven), bert.devries@pbl.nl (B. de Vries), detlef.vanvuuren@pbl.nl (D.P. van Vuuren), j.p.vandersluijs@uu.nl (J.P. van der Sluijs).

1 Tel.: +3130274 2046; fax: +3130274 4464 .

2 Tel.: +3130274 3533/253 3684; fax: +31 30274 4464/253 7601 .

3 Tel.: +3130253 7631; fax: +31302537601.
}

expectations for the future. The most clear-cut example is the difference between models that stem from a macro-economic tradition (top-down) [11,12] and those from a engineeringeconomic tradition (bottom-up) [6,7,13] that lead to different interpretations of the present situation with respect to energy efficiency (optimal vis-à-vis major opportunities for improvement) $[14,15]$. Even within one model, however, several options may exist on how to interpret the past and current situation. This may lead to different model calibrations, that cause uncertainty in future projections.

Different methods have been used to explore uncertainty in global energy models [16-19], but relatively little attention has been given to the influence of model calibration on future projections. We recently developed a method to analyse uncertainty in model calibration [20]. This method is inspired by the concept of equifinality, the phenomenon that there are many acceptable model calibrations that cannot easily be rejected and should be considered in assessing the uncertainty in predictions [21]. In this paper, we apply our calibration uncertainty method to the global energy model TIMER 2.0, a system dynamics model that simulates developments in global energy supply and demand [4,22]. While our previous publication focused on the development and proofing of the method, here our main interest is on the effect of model calibration on future scenarios for residential energy use at the regional scale. The main question is what the uncertainty in model calibration implies for the uncertainty in the future trends that this model simulates. 
Uncertainty studies of global energy models focus mainly on the global level [16-19]. However, with increasing regional disaggregation of these models, it becomes interesting to test their performance for individual regions We selected five world regions that are among the largest regions in terms of energy use and represent a wide spectrum of development levels: USA, Western Europe, India, China and Brazil. We focus on the residential sector, as this sector is currently the main energy consuming sector in many developing regions. Within this sector, the analysis focuses on energy demand - as recent uncertainty analysis of the TIMER model identified this as the most important factor in total model uncertainty [23].

In this paper, Section 2 introduces the role of uncertainty in the context of model calibration and the methodology to explore this uncertainty. Section 3 describes the structure of the TIMER 2.0 energy demand model. In Section 4, we analyse the performance of the model for residential energy use for historic energy use in several world regions. Section 5 presents the impact of calibration uncertainty on projections of energy use towards 2030. Finally, in Section 6 conclusions are drawn.

\section{Method for model calibration}

\subsection{Uncertainty in model calibration}

Exploration of different futures on the basis of models is complicated by many different sources of uncertainty [23-31]. This includes uncertainties associated with model parameters, but also those related to model structure or disagreements between conceptual theories on a larger scale. Some uncertainties can be reduced by additional knowledge (epistemic), while others are related to natural randomness (ontic). Beven [21] outlined a philosophy for modelling of environmental systems, focussing on the challenges in model calibration (an issue that has also been raised in [32,33]) Beven's approach rejects the idea that a single optimally calibrated model exists for any given case. Instead, environmental models may be non-unique in their accuracy of reproduction of observations (i.e. unidentifiable or equifinal), and subject to only a conditional confirmation, due to e.g. errors in model structure, calibration of parameters and period of data used for evaluation. An 'acceptable representation' of the model is called behavioural. The acceptance criterion can be quantitative (e.g. above a threshold value of a likelihood measure) or qualitative (e.g. reproduction of trends). For a more elaborate discussion on calibration uncertainty in energy modelling see [20].

At present, calibration of energy models is often based on the modeller's expert knowledge and skills to identify plausible parameter values. If multiple sets of parameter values are tenable and model projections are sensitive to the parameter values chosen, this practice is questionable and may overlook relevant sets of parameter values. A more systematic exploration of the uncertainty space can help to overcome this limitation.

\subsection{Methodology to for model calibration and scenario runs}

We developed an automated parameter estimation procedure to explore the impact of calibration uncertainty on model outcomes. The aim of the parameter estimation methodology is two-fold. First, it is an automated model calibration procedure that minimizes the error between model results and observations, generating a set of calibrated parameter values. In this sense it is related to nonlinear regression methods like PEST [34] or UCODE [35]. Second, by repeatedly applying the method it can be used to perform an uncertainty analysis on model calibration. This generates a series of calibrated sets of parameter values. This aspect is more related to (sequential) Monte Carlo based approaches like GLUE [36] or SimLab [37]. This method involves several steps:

A. Determining useful parameters for model calibration and their associated ranges.

B. Performing a series of model calibrations and identify sets of input parameters that perform well against historic data.

C. Analysing the sets of calibrated parameter values.

D. Analysing the impacts of calibration uncertainty on future projections.

The first step involves analysis of the model to select useful parameters for the model calibration process. We also identify ranges for the calibration parameters, based on analysis of the model formulation, the values used in former calibrations, literature and expert judgement. This step is described in detail in Section 3. The ranges are used as boundaries in the parameter estimation process.

Several measures exist to evaluate the deviation between model results (predictions, $P$ ) and observed data $(O)$ [38]. We choose to use the Normalised Root Mean Square Error (NRMSE), which is defined as:

$N R M S E=\sqrt{\frac{\sum_{t=1}^{T}\left(\frac{P_{t}-O_{t}}{O_{t}}\right)^{2}}{T}}$

In this, $P_{t}$ and $O_{t}$ indicate the predicted and observed value in year $t$ and $T$ is the number of years in the time series. This measure has values between zero (perfect fit) and infinite (random). Multiplied with 100 , the NRMSE can be seen as the time averaged percentage deviation between the time series of model results and the time series of observations.

In the second step, we perform a series of model calibrations. As starting point for these parameter estimations, we use an initial dataset (SI) for $P$ parameters and $N$ parameter estimation attempts: $S I_{P, N}$. This set contains a combination of design of experiments (central composite design [39], to explore the extremes of the parameter space) accomplished with a series of random numbers. In the model calibrations, the input parameters are varied simultaneously to minimize the NRMSE. We look for optimal parameter estimations by using a MATLAB build-in functionality for constrained nonlinear optimisation, using sequential quadratic programming [40]. This algorithm approaches the model as a blackbox optimisation function and varies the parameter values until the derivative of the objective function (i.e. the NRMSE) reaches values between zero and a pre-defined threshold level. This results in a dataset with calibrated parameter values that have a good (or best obtainable) fit with observations of energy use for the period 19702003: $S C_{P, N}$. This can be best imagined as the collection of local optima in the objective function landscape spanned up by the explored parameter space.

Third, we analyse the series of calibrated sets of parameter values in $S C_{P, N}$ in several ways. The distribution of the calibrated parameter values over their range is analysed and we plot the calibrated parameter values against the NRMSE. Relations between parameters and the impact of parameters on the NRMSE can be numerically expressed by the (linear) Pearson correlation coefficient between parameters. We use this as the simplest indicator to express a relation between two parameters, although it does not capture nonlinearity or the existence of multimodal distributions. Based on this, behavioural sets of parameter values can be selected. In our analysis, we decided not to remove any sets of parameter values based on non-behavioural outcomes. However, we use the NRMSE (hence, behavioural/non-behavioural) to weight future projections that are derived from the different sets of parameter values. 


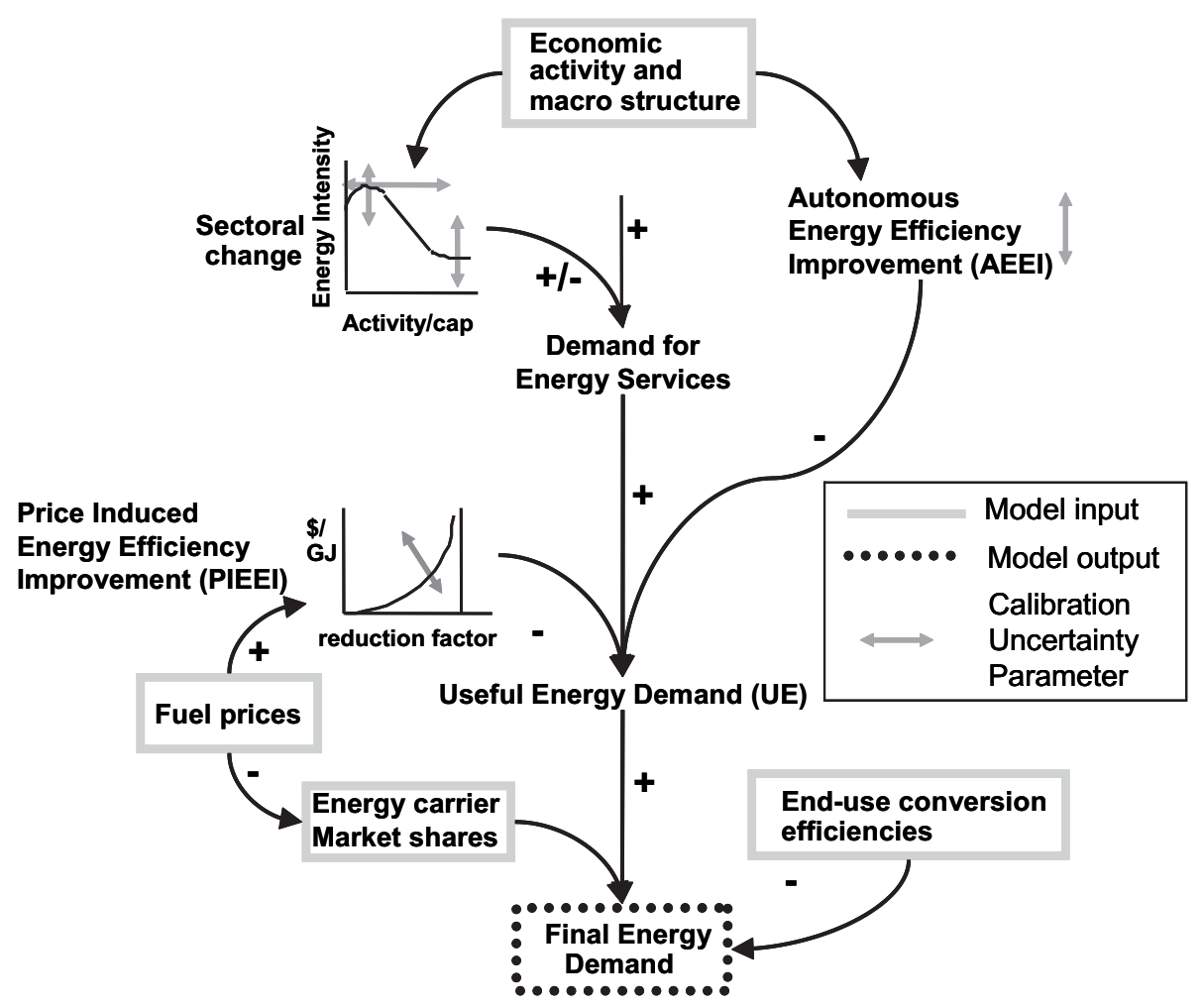

Fig. 1. Overview of the TIMER Energy Demand model and parameters used in he model calibration process.

The fourth step is to analyse the impact of variation in calibrated parameter values on future projections. We use the calibrated sets of parameter values (in $S C_{P, N}$ ) to run the model forward for the period 2003-2030. The range of projected future energy use scenarios is analysed by a frequency diagram of energy use in 2030. In this, the frequencies are weighted to the NRMSE. The weight $(W)$ that the $N$ 'th calibrated set of parameter values gets in the prediction ensemble is defined as the normalisation of the relative weight $(R)$ of the $N$ 'th set to the best performing set of parameter values ${ }^{4}$ :

$W_{N}=\frac{R_{N}}{\sum_{N} R_{N}}$ where $R_{N}=\frac{N R M S E_{\text {best }}}{N R M S E_{N}}$

\section{The TIMER 2.0 energy demand model: parameters and ranges}

The TIMER model is a system dynamics energy system simulation model [4,22] This model has been applied in a variety of contexts, for instance the IPCC Special Report on Emission Scenarios [41], UNEP Global Environmental Outlook [42] and the Millennium Ecosystem Assessment [43]. Energy use is modelled at a high level of aggregation; the model structure is similar for 26 world regions and five economic sectors and specific circumstances are captured by region- and sector specific parameter values. The energy demand model has a top-down macro-economic character: energy use is associated with economic activity via changes in energy intensity and efficiency (Fig. 1).

In a first step, energy use is modelled as the annual demand for Useful Energy (UE, i.e. the level of energy services or energy functions [4]). Useful Energy demand is a function of changes in

\footnotetext{
${ }^{4}$ This measure does not hold in the unlikely situation that the model exactly reproduces historic data and the best obtained NRMSE becomes zero.
}

population and economic activity and three dynamic factors: structural change in Useful Energy Intensity (UEI), Autonomous Energy Efficiency Improvement (AEEI) and Price Induced Energy Efficiency Improvement (PIEEI). The demand for useful energy is converted to secondary (or final) energy use (SE), using specific efficiencies $(\eta)$ for different fuels, capturing price-based fuel substitution. Thus:

$$
S E_{R, S, F^{(t)}}=\frac{P O P_{R^{(t)}} * X_{R, S^{(t)}} * U E I_{R, S, F^{(t)}} * A E E I_{R, S, F^{(t)}} * P I E E I_{R, S, F^{(t)}}}{\sum_{E C} \eta_{R, S, C^{(t)}} * M S_{R, S, C^{(t)}}}
$$$$
(\mathrm{GJ} / \mathrm{yr})
$$

in which $P O P$ is the population (in persons), $X$ is the per capita economic activity of a sector (for the household sector this activity indicator is private consumption in purchasing power parity (PPP), constant 1995 international \$/capita/yr). The useful energy intensity (UEI) multiplier captures intra-sectoral structural change (in GJ/ \$/capita) and the AEEI and PIEEI (dimensionless) multipliers represent autonomous and price induced efficiency improvements. UEI, AEEI and PIEEI are functions of other state variables in the model, which will be elaborated below. The market shares (MS) of fuels are derived from fuel prices via a multinomial logit allocation formula. The indices indicate region $(R)$, sector $(S)$, energy form $(F$, fuels or electricity) and energy carrier $(C$, coal, oil, natural gas, modern biofuel, hydogen, secondary heat and traditional biofuel). The model distinguishes two forms of energy, motivated by their different functions: electricity and fuels. For fuels, we focus on the total final demand i.e. the sum of all energy carriers ${ }^{5}$.

\footnotetext{
${ }^{5}$ It should also be noted that we assume no supply constraints by equating energy demand and energy use. The statistical data are assumed to have satisfied demand in a state of economic equilibrium on an annual basis. This might not be valid for developing regions, where electricity use is more limited by supply than by a lack of demand.
} 

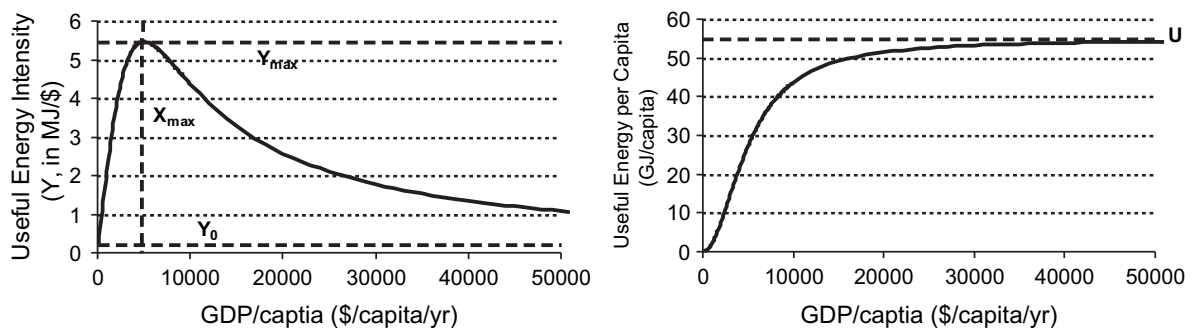

Fig. 2. UEI-curve (left) and useful energy use per capita (right) for hypothetical parameter values.

\subsection{Useful energy intensity}

From energy analysis some generic trends in energy use are known [44-46]:

1. Total energy use tends to increase with population and economic activity;

2. Energy intensity has been observed to increase, followed by a decline. This pattern is sometimes referred to as the environmental Kuznets Curve [47-49]. Underlying processes include changes in underlying activities (from little industry, to heavy industry and finally manufacturing industry) [50-52]. The level at which a maximum is reached tends to decrease over time - interpreted as the collective dissemination of energy-innovations and of learning-by-doing [53,54].

This stylized fact ${ }^{6}$ is represented in the TIMER model in the form of a (asymmetric) bell-shaped function of sector specific per capita economic activity. This is expressed as ${ }^{7}$ :

$U E I_{R, S, F^{(t)}}=Y_{0}+\frac{1}{\beta X_{(t)}+\gamma X_{(t)}^{\delta}}$

with $X_{(t)}$ the sectoral economic activity per capita and $\beta, \gamma$ and $\delta$ parameters to determine the shape of the curve. All parameters in this equation are defined per region, sector and energy form, $\delta$ is assumed to be negative to maintain a bell-shaped form.

For very high activity levels $(X \rightarrow \infty)$, UEI tends to reach asymptotically constant $\mathrm{GJ} / \$$ values, equal to $Y_{0} \mathrm{GJ} / \$^{8}$ (see Fig. 2 ). For very low activity levels $(X \sim 0)$ the $U E I$-value approaches $Y_{0}$ if $\delta$ is negative. The flexible formulation of this curve implies also a high sensitivity to parameter values. From an energy use point-ofview, some reasonable constraints can be made to limit the potential parameter space to a relevant subspace [20]:

- The value of $Y_{0}$ can be interpreted as the ultimately lowest energy intensity of sectoral activity in the both $X \rightarrow \infty$ and $X \sim 0^{9}$.

- The second term of the curve may, at high income levels, be related to saturation of useful energy per capita per year $(U)$, based on sector specific features such as climate or population

\footnotetext{
${ }^{6}$ The term 'stylized fact' stems originally from social sciences and economics and reflects a simplified representation of empirical findings. It is a broad generalization that emerges from many different data sources. It is mostly used in the context of macro-economic analysis, for instance when describing general relations of economic growth [55,56], linkages between economies [57] or the behaviour of stock markets [58] and currency markets [59].

7 This bell-shaped curve can also be written in terms of income elasticity as is common for energy use. It implies first rising, than declining income elasticity.

8 This asymptote coincides with a hyperbole of constant per capita energy use. The product of $X$ in $\$ /$ cap/yr and $Y(U E I)$ in $G J / \$ / y r$ is the per capita use of energy $(U)$ in $\mathrm{GJ} / \mathrm{cap} / \mathrm{yr}$.

${ }_{9} \alpha$ could be used to distinguish energy intensity between extremely high and low income levels.
}

density. Since we assume that $\delta$ is negative, assuming $Y_{0}=0$ in Eq. (4) (hence, focussing at the second term), means that:

$$
U=X^{*} U E I=\frac{X}{\beta X+\gamma X^{\delta}} \Rightarrow \lim _{X \rightarrow \infty} \frac{X}{\beta X+\gamma X^{\delta}}=\frac{1}{\beta} \text { and thus } \beta=\frac{1}{U}
$$

- The activity level at which the maximum occurs $\left(X_{\max }\right)$ can be estimated from regional energy use data. However, this has the risk of cyclical reasoning because one draws conclusions from the observed data which are to be explained ${ }^{10}$.

- The curve can be further constrained by forcing it through one observed reference point, defined as [ $\left.X_{\text {ref, }} U E I_{\text {ref }}\right]$, which can be any year in the period $1971-2003 .^{11}$

These constraints allow for a consistent set of parameter choices on the basis of three key variables: the activity level at which the maximum occurs $\left(X_{\max }\right)$, the saturation level of useful energy per capita $(U)$ and the asymptote or ultimate energy intentity $\left(Y_{0}\right)$.

The range for values of $X_{\max }$ and $U$ in the parameter estimation process is defined as $10 \%$ broader than the maximum and minimum values applied in earlier (manual) calibrations (see Appendix 1, Tables 5 and 6). Although $Y_{0}$ is conceptually only limited by the value of $U E I_{\text {ref, }}$, the model becomes linear if $Y_{0}$ approaches $U E I_{\text {ref }}{ }^{12}$. To ensure that the bell-shape of the function is maintained, we assume $Y_{0}$ to be lower than $20 \%$ of $U E I_{\text {ref. }}$.

\subsection{Autonomous energy efficiency improvement (AEEI)}

The continuous decline of energy intensity due to technology improvement is represented by the Autonomous Energy Efficiency Improvement (AEEI) multiplier. The marginal AEEI is formulated as a fraction of economic activity growth [60]:

$A E E I_{\operatorname{marg} R, S(t)}=F_{S} *\left(\frac{G D P p c_{R(t)}}{G D P p c_{R(t-1)}}-1\right) * 100 \quad(\% / \mathrm{yr})$

in which $F_{S}$ is a sectoral specific fraction of economic activity growth.

The parameter value that has to be estimated for $A E E I$ is the fraction of GDP growth $\left(F_{S}\right)$. For the percentage of annual AEEI a range of $0.2-1.5 \%$ per year is suggested by experts [17]. We established a range for $F_{S}$ based on the average annual regional GDP

\footnotetext{
10 One should do this only for datasets (regions, periods) where presumably enduse conversion efficiency has hardly changed. This is probably valid for electricity use, but not for fuel use, especially in developing regions. The transition from traditional biomass to modern fuels leads to major efficiency improvements, see $\eta$ in Eq. (2).

11 In the default model implementation this is the year 2003, the latest year of the calibration period.

12 Since energy intensity is defined in energy use per (monetary) unit of GDP, there is no theoretical or thermodynamic limit to the value of $Y_{0}$.
} 
per capita growth over the period 1971-2003 (see Appendix 1, Table 7). Though we estimate the value of the parameter $F_{S}$, we present the results of the AEEI in Section 4 as the average percentage of annual efficiency improvement.

\subsection{Price induced energy efficiency improvement (PIEEI)}

The PIEEI reflects that energy efficiency measures are more attractive if energy prices are high. The description of PIEEI is based on an energy conservation supply-cost-curve, describing the increasing marginal cost to save energy. The investments are annuitied by assuming a payback time. By comparing the annual gains of efficiency improvement to the annual cost of investments, an optimum investment (or efficiency) level can be found. The energy conservation supply-cost-curve can be compared to bottom-up technology data [4] but is modelled as an aggregated function. The optimal level of energy efficiency ( $E$, as fraction of total energy use) is defined as:

$$
E_{R, S, F(t)}=M_{R, S, F}-\frac{1}{\sqrt{M_{R, S, F}^{-2}+\frac{C_{R, S, F(t) * T_{R, S, F(t)}} S_{R, S, F} I_{R, S, F(t)}}{2}}}
$$

in which $M$ is the maximum potential price induced efficiency improvement, $C$ the sectoral average costs of useful energy (\$/GJUE) and $T$ the payback time. $I$ is the cost curve decline from learning-bydoing and the parameter $S$ is used to scale the curve to the sector specific costs of useful energy. The PIEEI on marginal capital investments, as used in Eq. (3), is a defined as: $1-E_{R, S, F}$. Vintage modelling of energy demand capital delays the impact of the PIEEI, because the current PIEEI is the weighted average of the marginal PIEEI over the capital life time.

In the parameter estimation procedure we vary values of payback time $(T)$ and learning $(I)^{13}$. Because the actual PIEEI is dependent on the energy prices, we express the results of the PIEEI as the cumulative efficiency improvement between 1971 and 2003. The ranges for the learning and payback time parameters in the experiment are shown in Appendix 1, Tables 5 and 6.

\subsection{Price-based fuel substitution}

Market shares for fuels in TIMER are allocated on the basis of mutual cost differences, using a multinomial logit formulation. To simplify our calculations, we decided in this analysis to fix market shares to historic data and use a scenario for market share development, based on the development of energy prices in a standard future scenario (see Section 5). Effectively, this keeps the denominator in Eq. (3) the same in all model runs.

\section{Simulation of historic energy use in five world regions}

\subsection{Residential energy use in the USA}

Total residential sector fuel use in the USA declined in the 19712003 period from about 9 to $7 \mathrm{EJ} / \mathrm{yr}$ (Fig. 3,) [61]. In the same period, the assumed drivers, private consumption and population, increased [62]. Also, floor space per capita, an important bottom-up driver of space heating, increased $[63,64]$. The decline has been driven by an

\footnotetext{
13 Alternative parameters to vary would be the maximum improvement level $(M)$ or the steepness $(S)$. However, $M$ is based on a theoretical maximum efficiency improvement expressed in energy intensity terms. This is a useful parameter to explore, but has more impact on future projections than on historic calibration. The steepness parameter $(S)$ is used to scale the PIEEI curve to the useful energy costs per sector and is therefore not useful to vary.
}

improvement in conversion efficiencies, largely due to the gradual switch from coal to oil and then, partly, to natural gas [61]. The use of traditional fuels has been minor, with a temporal increase during the oil crisis. The data show many year-to-year fluctuations, which correlate strongly with warmer and colder years, expressed in heating-degree-days. Correcting fuel use for temperature fluctuations smoothes the historic data, but does not change the decreasing trend [65]. The TIMER model is capable to simulate the declining trend, with a best obtained NRMSE of $6.7 \%$. There is a rather broad spread, with some (outlying) sets of parameter values even showing an increasing trend (with NRMSE 18\%). The parameter settings indicate declining useful energy intensity in the 1971-2003 period, with only minor variation in the UEI related parameters. A rather wide range of technological (AEEI) and price-related (PIEEI) factors can explain the historic trends (Appendix 2, Fig. 6).

Residential electricity use in the USA has been increasing rapidly from 2 to $4.5 \mathrm{EJ} / \mathrm{yr}$ in the 1971-2003 period (Fig. 3) [61]. The most important underlying drivers are ownership of appliances and lighting [63]. The trend can be simulated with a best-fit of $3.6 \%$ and all calibrated sets of parameter values have NRMSE values below 6.5\%. Although there is little correlation between the calibrated parameter values (Table 2), two implementations of the UEI-curve are distinguished. The best fitting sets of parameter values are characterised by a combination of high $X_{\max }$ and low $Y_{0}$ (i.e. historically increasing $U E I$ ), moderate technology improvement (AEEI around $0.6 \% / \mathrm{yr}$ ) and low values for price induced efficiency improvement. This implies a significant income elasticity and a small price-elasticity, whereas technology is of moderate importance. Another behavioural implementation involves low values of $X_{\max }$ (i.e. historically decreasing energy intensity), no technology development and moderate reactions to price changes.

\subsection{Residential energy use in Western Europe}

Western European ${ }^{14}$ residential fuel use has been stable for the last 30 years at about $8 \mathrm{EJ} / \mathrm{yr}$ (Fig. 3), with a gradual replacement of coal by oil and then natural gas [61]. Much of the short term variation can be explained from temperature fluctuations [65]. The trend of the data can be simulated by the model with best NRMSE values of $4.3 \%$. There is no correlation in parameter values (Table 1) indicating that there are no patterns between the different calibrated parameters. The most behavioural sets of parameter values are characterised by a UEI-curve that is rather similar to the USA, with low values for $X_{\max }$ and $Y_{0}$, but a higher value for $U$. Technology development (AEEI of $0.5-0.7 \% / \mathrm{yr}$ ) and a moderate (if any) role for price induced savings $(P I E E I \approx 0)$ explain the historic data.

Electricity use has been increasing rapidly in Western Europe, though after 1985 with a lower growth rate [61]. With NRMSE values between 8.5 and $14 \%$, the model is capable to simulate the growth but not the decline in growth rate. Table 2 shows some equifinality in the values for UEI and AEEI, although both parameters strongly determine the NRMSE. The best fitting sets of parameter values have high $X_{\max }$, low $Y_{0}$ and low AEEI and PIEEI values, which indicate the importance of activity growth as a determinant of electricity use and the lack of price effects.

\subsection{Residential energy use in Brazil}

For developing regions it is important to realise that some caveats are in place. First, the data in developing regions,

\footnotetext{
14 The region of OECD Europe in the TIMER model is comparable to EU15 plus Norway and Switzerland.
} 
Fuel
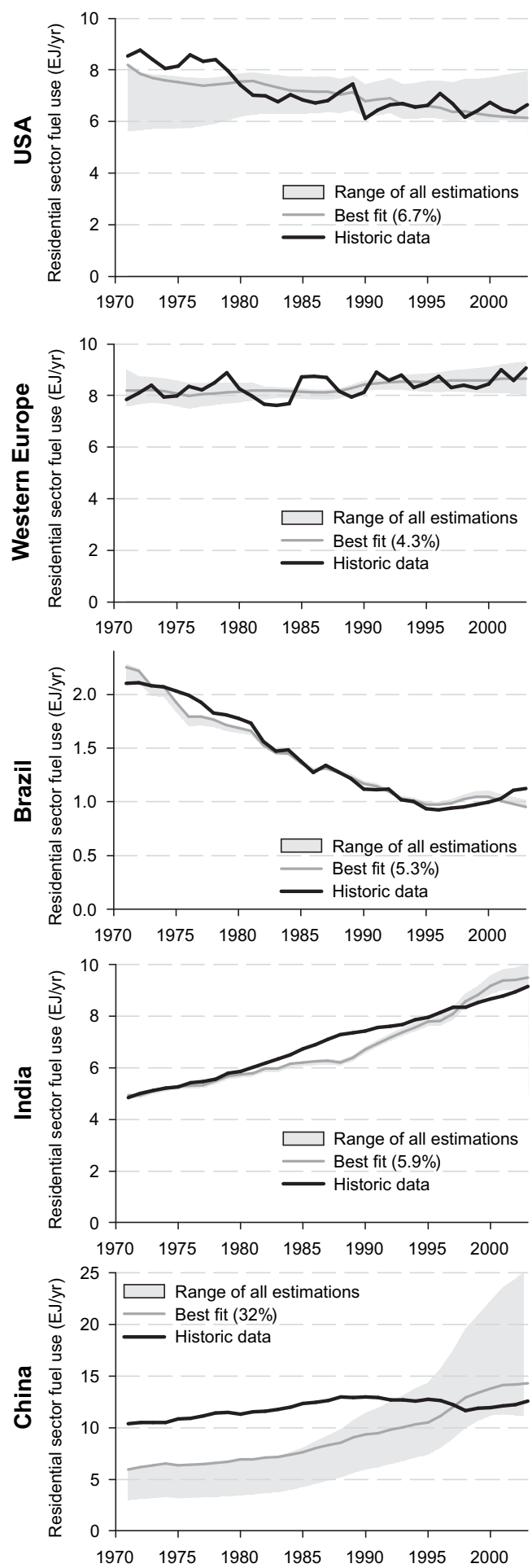

Electricity
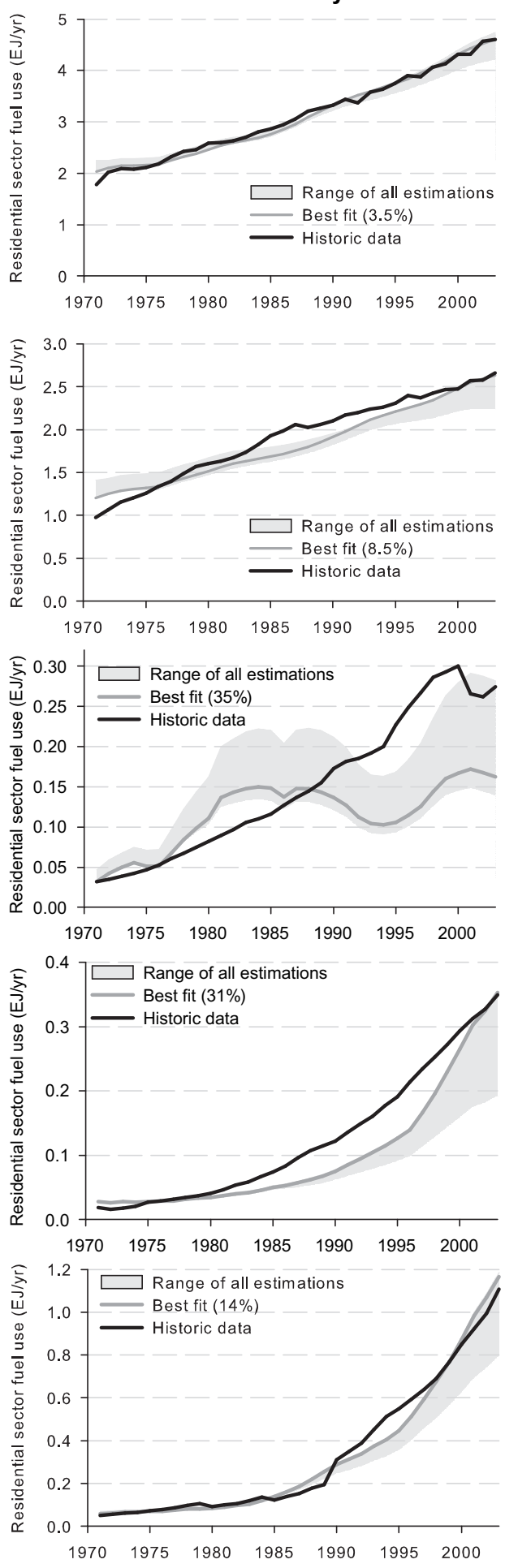

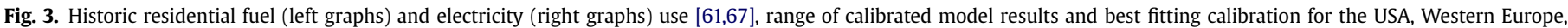
Brazil, India and China.

especially pre-1990, are notoriously unreliable. Second, the large income disparities within urban areas and between urban and rural areas may make the average income an unsuitable driving force indicator (see also Refs. $[48,66]$ ). Third, market institutions are often partly or sometimes hardly functioning, this influences among others the dissemination of technologies and the role of prices [14].
Brazilian total final energy use is characterised by a rapid decline of traditional fuels [67], although the rate of decrease slows down in recent years [68], also in the residential sector $[69,70]$ (Fig. 3). Especially during the 1980s the share of modern (renewable) energy sources in total energy use decreased as a result of policies adopted in the 1970s [71]. These policies were mainly driven by energy import policy and focused on the 
Fuel
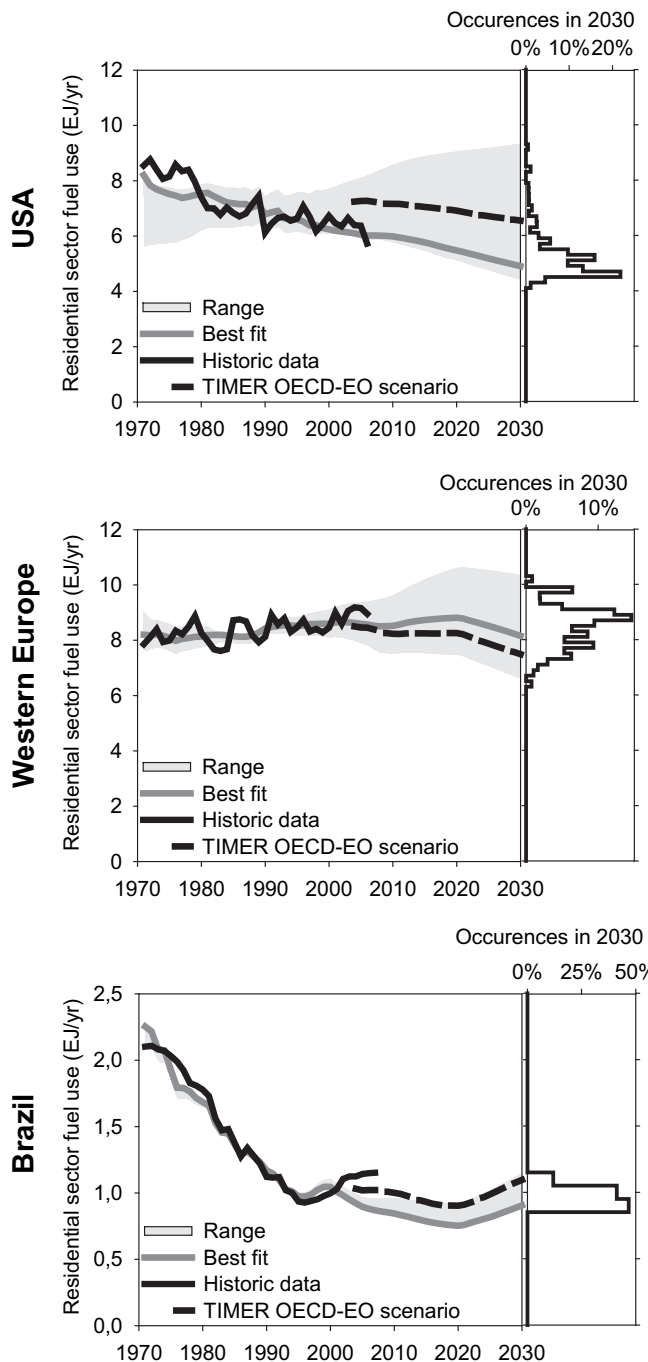

Occurences in 2030

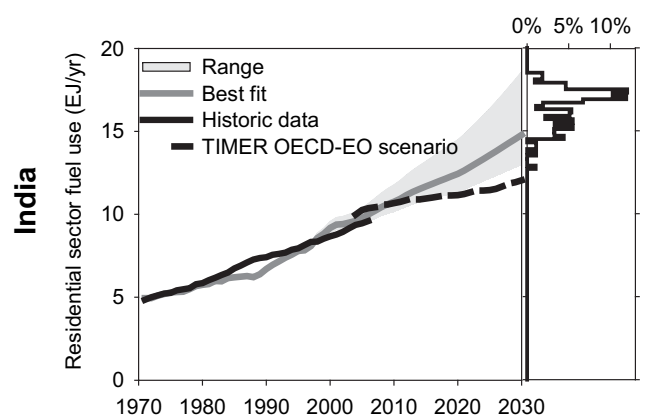

Occurences in 2030 $\begin{array}{lll}0 \% & 10 \% & 20 \%\end{array}$

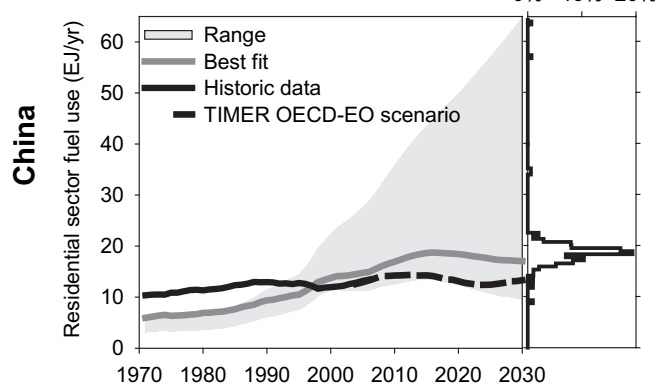

\section{Electricity}

Occurences in 2030 0\% 10\% $20 \%$

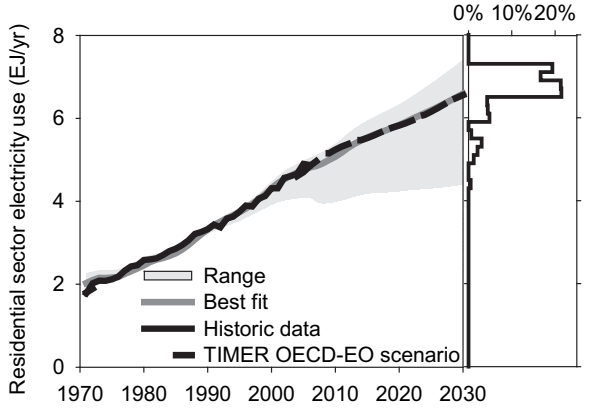

Occurences in 2030 $0 \% \quad 20 \% \quad 40 \%$

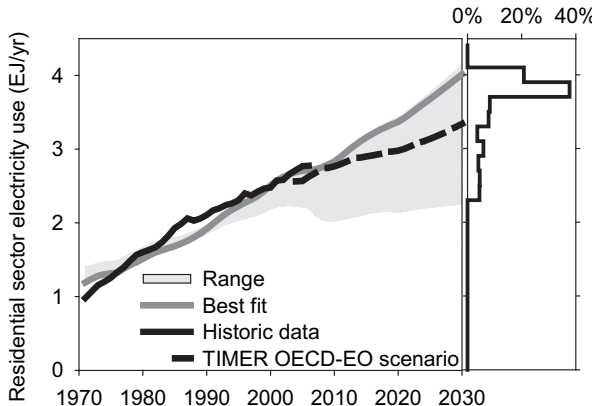

1970198019902000201020202030

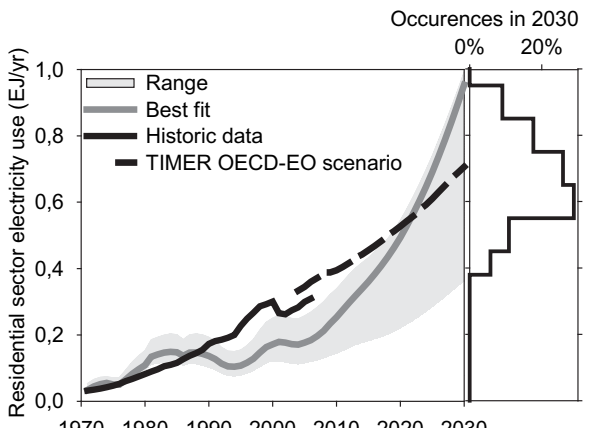

1970198019902000201020202030
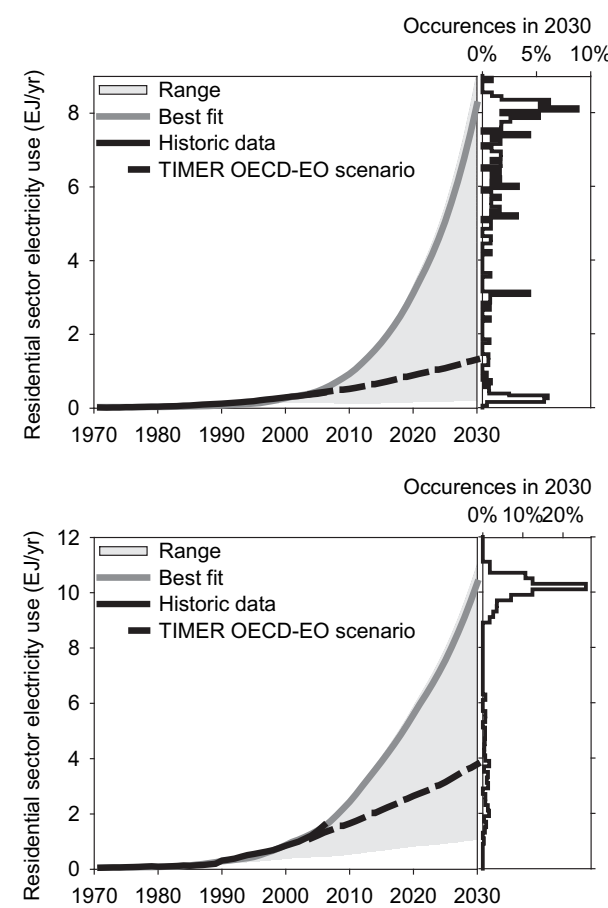

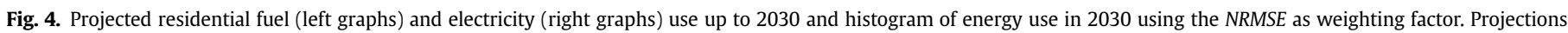
based on OECD-EO scenario inputs and calibrated parameter sets. 
Fuel

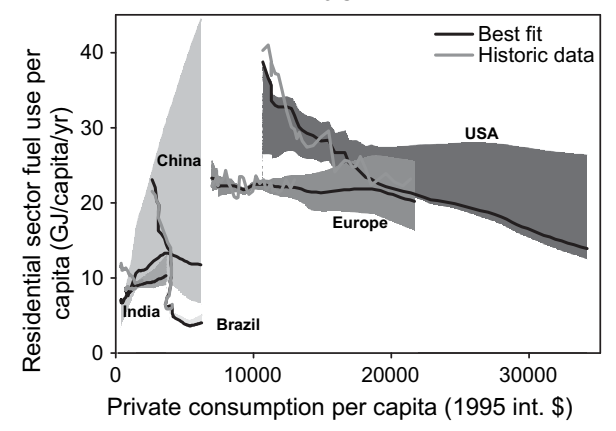

Electricity

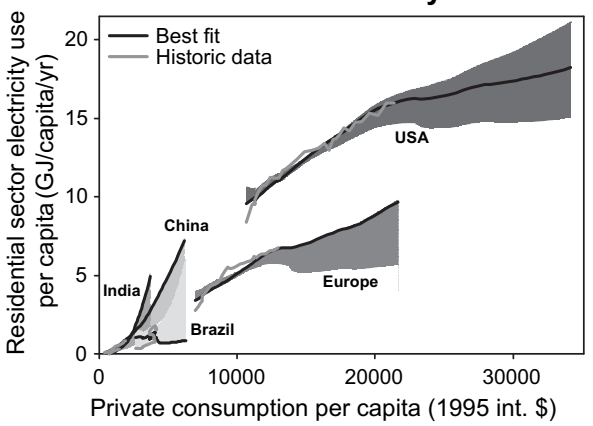

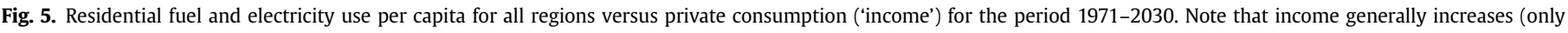
Brazil had some periods of decrease) and regions do not reach similar income levels at the same time.

transport sector (i.e. the alcohol program). The major commercial fuel in the residential sector is LPG, mainly applied for cooking; space heating is almost nonexistent in Brazil [72]. Explanations for the rapid decrease of fuelwood are substitution by LPG and improved efficiency. The model is able to simulate fuel use rather well, with NRMSE values of 5.4\%. However, this is strongly influenced by changing the model assumption of constant efficiency for traditional fuels before 1985 towards a linear increase from 5\% (1971) to 15\% (1985), reflecting large scale implementation of improved stoves. The parameter values indicate various possible UEI-curves ( $X_{\max }$ has values both below and above the 2003 private consumption level and can thus historically be both decreasing and increasing) leading to different stabilisation level (wide variation in $U$ ). Technology improvement has been important, with AEEI values between 0.5 and $0.8 \% / \mathrm{yr}$. However, responses to prices (PIEEI) are unimportant in explaining historic developments. The equifinality between parameters takes mainly place within the UEI-curve and does not appear in Table 1.

The use of electricity in Brazil is increasing rapidly, mainly driven by the increased ownership of (energy intensive) appliances [67,72]. Compared to other developing countries, Brazil has high ownership of electric appliances [73]. One peculiar - and disturbing phenomenon in simulating Brazil's energy use are fluctuations in the major driver (private consumption) [62] and the sometimes extremely high inflation rate which makes the monetary time series

Table 1

Pearson's linear correlation coefficient between calibrated parameter values for residential fuel use. Chinese fuel use is considered non-behavioural.

\begin{tabular}{llll}
\hline USA & UEI $\left(Y_{\max }\right)$ & AEEI & PIEEI \\
AEEI & 0.36 & - & - \\
PIEEI & 0.23 & -0.04 & -0.60 \\
NRMSE & -0.47 & -0.53 & PIEEI \\
India & UEI $\left(Y_{\max }\right)$ & AEEI & \\
AEEI & 0.31 & - & - \\
PIEEI & -0.30 & -0.33 & 0.14 \\
NRMSE & -0.98 & -0.36 & PIEEI \\
Brazil & $U E I\left(Y_{\max }\right)$ & AEEI & \\
AEEI & -0.03 & - & - \\
PIEEI & -0.02 & -0.54 & 0.14 \\
NRMSE & 0.07 & -0.84 & PIEEI \\
Europe & $U E I\left(Y_{\max }\right)$ & AEEI & \\
AEEI & -0.30 & - & - \\
PIEEI & 0.06 & -0.25 & 0.15 \\
NRMSE & 0.07 & 0.08 & PIEEI \\
China & $U E I\left(Y_{\max }\right)$ & AEEI & \\
AEEI & 0.29 & - & - \\
PIEEI & -0.13 & -0.29 & 0.07 \\
NRMSE & -0.37 & -0.84 & \\
\hline & & &
\end{tabular}

probably a bad indicator of activity see Ref. [65]. Brazilian residential electricity use is difficult to simulate with the model (Fig. 3). In periods of constant or declining private consumption levels, historic electricity use increased linearly. This is probably due to the uncoupling of real activity levels and monetary data due to high inflation rates, but in addition it might be that the growth of electricity use in Brazil might be supply-driven by slowly expanding capacity.

\subsection{Residential energy use in India}

Indian residential fuel use increased linearly between 1971 and 2003 (Fig. 3) [67], although private consumption increased exponentially [62]. Residential fuel use in India is mainly applied for cooking and lighting (kerosene lamps); space heating is not important due to India's (sub-) tropical climate [74]. Air conditioning is still a luxury, although ownership is increasing in recent years [75]. Residential fuel use is dominated by traditional fuel use. The use of commercial fuels increased, though this is limited in absolute terms. Government policies such as social price subsidies on electricity, kerosene and LPG and electrification of rural households strongly influence energy use, although it is hard to quantify how in the absence of equivalents for comparison [76]. The trend of fuel use can be reproduced by the model with a best NRMSE of 5.9\%. The behavioural sets of parameter values are characterised by declining energy intensity, low AEEI and hardly

Table 2

Pearson's linear correlation coefficient between calibrated parameter values for residential electricity use. Brazilian electricity use is considered non-behavioural.

\begin{tabular}{llll}
\hline USA & UEI $\left(Y_{\max }\right)$ & AEEI & PIEEI \\
AEEI & 0.04 & - & \\
PIEEI & 0.17 & -0.30 & - \\
NRMSE & 0.75 & 0.37 & 0.48 \\
India & $U E I\left(Y_{\max }\right)$ & $A E E I$ & PIEEI \\
AEEI & -0.31 & - & \\
PIEEI & -0.12 & 0.65 & - \\
NRMSE & -0.32 & 0.75 & 0.07 \\
Brazil & $U E I\left(Y_{\max }\right)$ & AEEI & PIEEI \\
AEEI & 0.02 & - & \\
PIEEI & -0.03 & -0.25 & - \\
NRMSE & -0.19 & 0.05 & -0.61 \\
Europe & $U E I\left(Y_{\max }\right)$ & AEEI & PIEEI \\
AEEI & -0.54 & - & \\
PIEEI & -0.11 & -0.14 & - \\
NRMSE & -0.89 & 0.81 & 0.04 \\
China & $U E I\left(Y_{\max }\right)$ & AEEI & \\
AEEI & 0.10 & - & PIEEI \\
PIEEI & 0.01 & -0.26 & - \\
NRMSE & -0.32 & 0.75 & 0.07 \\
\hline
\end{tabular}


any PIEEI. Variation in parameter values is only observed for $U$. This means that technology (AEEI) and price-impacts (PIEEI) play no role in the explanation of Indian residential fuel use and that it can fully be explained from income related changes (UEI).

The level of residential electricity use in India is very low, but shows an exponentially increasing trend [67]. It can hardly be simulated by the model: the best NRMSE is $31 \%$. In the parameter values of AEEI and PIEEI play no role and electricity use is determined by rapidly increasing useful energy intensity. A possible explanation (for India, but also for China and Brazil, discussed further on) is that the demand for electricity is only partly met, due to constraints in power generation, transmission and distribution. It is well known that in many parts of India, electricity shortages happen with subsequent outages and allocation schemes [77].

\subsection{Residential energy use in China}

Chinese residential fuel use increased slowly from about 10 to $12 \mathrm{EJ} / \mathrm{yr}$ (Fig. 3) [67]. Rural household fuel use in China consists almost solely of traditional fuels and coal [78], while urban households use mainly electricity and gas, LPG and coal [79]. Residential coal use declined rapidly during the 1990s, coinciding with a government campaign to close down small and unsafe mines $[80,81]$. The model has difficulties to combine the data series on the model drivers (both population and income increased strongly) with the historic data on energy use (which are nearly constant). The bestfit shows an exponentially increasing trend with an NRMSE of only $32 \%$. The UEI-formulation assumes at these low income levels a close relation between energy and income; AEEI or PIEEI cannot offset this trend within the allowed value-range. Two alternative sets of parameter values lead to a better fit, but both are allegedly implausible. First, extremely low values for $X_{\max }(10 \$ /$ cap/yr) and $U(3 \mathrm{GJUE} /$ cap/yr) combined with high AEEI values (6\%/yr) lead to a historically constant energy use, but also to rapidly declining future projections. A second option is to increase the value of the reference UEI in 2003 (see Section 3.1), but this implies higher end-use conversion efficiencies ( $\eta$ in Eq. (2)), which is rather implausible [78]. Further explanations may be related to data quality ${ }^{15}$ or very high efficiency improvements resulting from large inefficiencies in 1971 that cannot be reproduced by the current model.

Residential electricity use does follow an exponential trend [67] and can be reproduced quite well with the exponentially rising private consumption [62]. Because the data show some short term deviations from the exponential trend (which are likely to be data errors or supply-shortages) the best-fit has still a rather high NRMSE value of $14 \%$. The parameter values for the best fitting sets of parameter values are characterised by relatively rapidly increasing useful energy intensity, with a peak a relatively high income levels (20-30000 int\$/capita). Technology (AEEI) and price (PIEEI) play hardly any role in explaining the historic trend (Appendix 2, Fig. 7). Although there is variation in parameter values (Fig. 7), this is mostly within the UEI-curve and no pattern between the values of UEI, PIEEI and NRMSE can be observed (Table 2).

\subsection{Differences and patterns in parameter values}

While we have seen that the model can reproduce some trends in regional energy use very well, the model results on fuel use in China are not behavioural with historic data. With respect to electricity use, India and China can be regarded behavioural, despite their relatively high NRMSE values, but Brazil is clearly not behavioural. These non-

\footnotetext{
15 It should be note that pre-1990 levels of traditional fuel use in China are constant in this dataset.
}

behavioural sets of parameter values provide no useful information on the model parameter values and they should not be used to analyse patterns or differences. Also forward calculations on the basis of these sets of parameter values are not useful.

What are the differences in parameter values between the regions? The parameter values for residential fuel use show that all UEI-curve implementations (except Brazil) are historically declining with hardly any base-intensity and comparable levels of saturation of approximately $30 \mathrm{GJUE} / \mathrm{yr}$ (except for the USA, Appendix 2, Fig. 6). Peculiarly, the USA and Europe have the lowest stabilisation levels of useful energy, despite differences in temperature and the demand for space heating. This uncovers a weakness of our method, in which each region is calibrated to its own historic data without any reference to other regions (this issue is discussed below in more detail). Here, it leads to extrapolation of the decreasing trends in Europe and the USA and the increasing trends in developing countries. Technology improvement is relatively important in explaining historic fuel use, with average values for AEEI between 0.5 and $1.2 \% / y r$. Price induced changes seem unimportant in all regions, except for the USA.

For electricity use, the calibrated useful energy intensity curves are historically increasing for all regions ( $X_{\max }$ is higher than 2003 private consumption levels), except for the USA (Appendix 2, Fig. 7). Further, UEI is in all regions characterised by a low base level $\left(Y_{0}=0-0.02 \mathrm{MJ} / \$ / \mathrm{yr}\right)$. Useful energy use per capita saturates at about $70 \mathrm{GJUE} / \mathrm{capita} / \mathrm{yr}$ for all regions. Technology and priceimpacts are unimportant in all regions, with all AEEI values below $0.5 \% / y r$ and hardly any PIEEI.

\section{Uncertainty in projections for $\mathbf{2 0 3 0}$}

\subsection{Energy use projections for five world regions}

An important question is how calibration uncertainty influences future projections of the model. Therefore, we use the sets of calibrated parameter values to determine for forward calculations towards 2030. We use scenario inputs from the Environmental Outlook scenario of the Organisation for Economic Co-operation and Development: the OECD-EO scenario [82-84]. These scenario inputs include projections for private consumption and population. The OECD-EO is a baseline scenario without new policies on economy and environment, including moderate projections of population and economy (though a rather high economic growth in developing regions). In this analysis, the share of final energy carriers is the same in all forward calculations, corresponding to energy prices in the default implementation of this scenario ${ }^{16}$. The TIMER model has also been used within the OECD-EO study to project developments of the future energy system. The parameter settings for that study were globally calibrated against the IEA World Energy Outlook [85] and are quite different from the ones we use here. These projections are shown for comparison in subsequent graphs, indicated as TIMER OECD-EO scenario. We also compare these projections with more recent data, which are currently available up to 2006.

For fuel use in Western Europe, the range of projections from the calibrated sets of parameter values broadens after 2000, resulting in projections between 6 and $10 \mathrm{EJ} / \mathrm{yr}$ in 2030 (Fig. 4). Expressed as relative deviation of the best fitting set of parameter

\footnotetext{
${ }^{16}$ Normally energy prices for future projections are calculated endogenously in the model based on depletion of resources and learning of exploitation technology. If this were included, different energy demand projections would lead to different energy prices, causing different market shares of fuels and diverging values for enduse-efficiency and PIEEI.
} 
Table 3

Pearson's linear correlation coefficient between parameter values and projected residential sector fuel use in 2030 (left). The right column contains the range of projected fuel use in 2030 as percentage of the best-fit projection. The calibration of Chinese fuel use is considered non-behavioural.

\begin{tabular}{lllrll}
\hline & UEI $\left(\mathrm{Y}_{\max }\right)$ & AEEI & PIEEI & NRMSE & Range in 2030 \\
\hline USA & -0.46 & -0.52 & -0.56 & 0.91 & $100 \%$ \\
Europe & 0.25 & -0.09 & 0.05 & 0.22 & $46 \%$ \\
India & -0.79 & -0.82 & 0.36 & 0.82 & $38 \%$ \\
China & -0.31 & -0.87 & 0.03 & 0.79 & $324 \%$ \\
Brazil & -0.06 & -0.87 & 0.20 & 0.93 & $27 \%$ \\
\hline
\end{tabular}

values, this amounts to a range of $46 \%$ (Table 3 ). The projection of the best fitting set of parameter values is in the middle of this range and in the peak of the weighted distribution of projections in 2030: slightly over $8 \mathrm{EJ} / \mathrm{yr}$ in 2030. It should be noted that in the OECD-EO scenario, residential fuel use in Western Europe is projected to remain stable until 2030 at about $8 \mathrm{EJ} / \mathrm{yr}$, with a slight decrease after 2020. For electricity use, the calibrated scenarios based on this paper lead to an electricity use of $4 \mathrm{EJ} / \mathrm{yr}$ in 2030. The range of future projections on the basis of calibrated sets of parameter values for 2030 are between 2 and $4 \mathrm{EJ} / \mathrm{yr}$, or $43 \%$ relative to the best-fit projection (Table 4 ). The OECD-EO projection for electricity use in Europe is within this range (Fig. 4).

For fuel use in the USA, the distribution in 2030 shows that the wide range of projections (100\% of the best-fit) originates mostly from a few outliers: the majority of calibrated sets of parameter values follow the decreasing trend of historic data (Fig. 4). Electricity use in the USA for both the best-fit set of parameter values is projected at the level where most projections are clustered: 6-7 EJ/yr in 2030 (there is also a range of only $34 \%$ around the best-fit, see Table 4).

Projections for Brazilian fuel use show a relatively narrow range around the OECD-EO scenario (only $27 \%$ of the best-fit) and are stable at about $1 \mathrm{EJ} / \mathrm{yr}$. However, more recent data follow a slightly higher path. The simulation of electricity use was considered non-behavioural is and is not further discussed. For India (Fig. 4) the range for residential fuel use projects $13-18 \mathrm{EJ} /$ $\mathrm{yr}$ in 2030 (or $38 \%$ range). These projections are considerably above the OECD-EO scenario, and recent data are not decisive. Projections for electricity use diverge far more. The best-fit set of parameter values and the full range indicate exponential growth towards $7 \mathrm{EJ} / \mathrm{yr}$ (with a range of $82 \%$ around the best-fit). The OECD-EO scenario has much lower numbers (1.8 EJ). Data for the period 2003-2006 indicate a lower electricity use, in line with the OECD-EO scenario. For China, the calibration of fuel use is not behavioural and is not discussed here. For electricity use, projection increase rapidly to about $10 \mathrm{EJ} / \mathrm{yr}$ (Fig. 4), though with a range of $58 \%$. The OECD-EO scenario is much lower, at $4 \mathrm{EJ} / \mathrm{yr}$. Data for the period 2003-2006 show that China might be on the high growth path.

\section{Table 4}

Pearson's linear correlation coefficient between calibrated parameter values and projected residential electricity use in 2030 (left). The right column contains the range of projected electricity use in 2030 as percentage of the best-fit projection. The calibration of Brazilian electricity use is considered non-behavioural.

\begin{tabular}{lclrrr}
\hline & UEI $\left(Y_{\max }\right)$ & AEEI & \multicolumn{1}{c}{ PIEEI } & NRMSE & Range in 2030 \\
\hline USA & -0.48 & -0.49 & -0.21 & -0.70 & $34 \%$ \\
Europe & 0.86 & -0.84 & 0.05 & -0.99 & $43 \%$ \\
India & 0.51 & -0.86 & -0.75 & -0.96 & $82 \%$ \\
China & 0.49 & -0.55 & -0.27 & -0.88 & $58 \%$ \\
Brazil & 0.11 & -0.37 & -0.76 & 0.69 & $160 \%$ \\
\hline
\end{tabular}

\subsection{Evaluation of projections, model and method}

The result show that the uncertainty in calibration leads to wide ranges of future projections ${ }^{17}$. In this context, it is interesting to see the influence of individual parameters on these projections (as a result of the non-linear nature of the model this cannot be easily seen). The simplest method to identify these influences is the linear correlation between the calibrated parameter values and projected energy use in 2030 (Tables 3 and 4). In line with expectations, technology improvement (AEEI) correlates negatively with future energy use, though its influence varies between regions and is not necessarily related to regions with high AEEI values. Usually price induced improvement should also be negatively correlated with future energy use, since energy prices are projected to increase. However, in many regions the PIEEI plays no role and has values close to zero (hence, outliers easily disturb the correlation coefficient). The role of energy intensity changes differs between fuel and electricity use. For fuel use, most regions have the peak of the UEIcurve at historic income levels, projecting declining energy intensity and thus a negative (though weak) correlation. For electricity use, the peak is mostly at future income levels, and energy intensity is increasing towards 2030, leading tot positive (but also weak) correlations. This implies that structural change is an important factor behind rapidly growing electricity demand in developing countries.

In our calculations, each region was calibrated separately, to obtain model results that better match historical data. Originally, however, the useful energy intensity curve has been proposed as 'stylized fact' from cross-regional data, covering a large GDPspan over the 1971-2003 period [4,49]. According to this view, the paths that other regions have taken previously might be an indicator for other regions. This could lead to different projections. For instance, residential energy use in India is calibrated here towards data from a period in which lighting is the major electricity function; a possible future rise in space cooling or energy intensive appliances cannot be foreseen in these data but can be obtained from a comparison with the USA. A plot of energy use per capita versus private consumption for the period 1971-2030 reproduces the general shape of rapidly increasing annual energy use per capita at low income levels and saturation at higher levels (Fig. 5). The historical data and our results clearly indicate that Brazil and China with declining per capita energy consumption do not match this pattern. The historical and projected curves for Europe suggest constant per person energy use and for the USA a further decline, both to be interpreted as signs that saturation and ongoing energy efficiency improvements continues. Because space heating accounts for $60-80$ percent of residential fuel use $[63,86]$, it is not to be expected that the low income regions India and Brazil will follow the European and USA experiences. This can be accounted for by correcting the data for heating-degree-days. Explicit modelling of heating and cooling demand is another option to overcome this issue [87].

Based on our calibration experiments, per capita residential electricity use is projected to increase with rising income for all regions, and there is (still) no sign of saturation for the developed regions (Fig. 5). The differences between Europe and the USA are rather outspoken and the best fitting projections for the developing regions indicate a growth to American levels of residential electricity use. However, the ranges for India and

\footnotetext{
17 These models are often used to make projections towards 2050 or 2100.
} 
China show that an increase towards European levels is also possible.

\section{Discussion and conclusion}

In this paper, we analysed impact of uncertainty in the calibration of the TIMER residential energy demand model on future projections for several world regions. The results lead to the following conclusions.

The TIMER global energy demand model is able to reproduce regional historic energy data on the basis of multiple sets of parameter values (equifinality). In the model calibration, a range of parameters values is found to provide reasonable model calibration. In general, there is a trade-off between the technology development parameter (AEEI) and changes in useful energy intensity ('income elasticity').

The model generally performs better for developed regions than for developing regions. Residential fuel use in India and Brazil, and electricity use in China can be well simulated. However, simulations of fuel use in China and electricity use in Brazil are clearly not behavioural. The formulation of energy demand on the basis of changes in useful energy intensity, technology development and energy price response is apparently insufficient for developing countries. For instance, energy prices in India are heavily subsidised and there is a lack electricity production capacity. China has similar problems, and also closed down small-scale coal mines. In Brazil, high inflation rates and periods of decreasing income complicate the relation between economic activity and energy use.

Uncertainty from model calibration can have significant impact on future projections. We find that the different sets of parameter values lead to a wide range of future projections. Already in 2030 there is a bandwidth of $27-100 \%$ around the 'best-fit' in most regions. This variation can be mostly understood from a different balance in settings of energy intensity and efficiency improvement.

Because the uncertainty in model calibration has a significant influence on future projections of energy models, modellers should systematically account for this source of uncertainty and communicate the bandwidth of possible projections with future scenarios. This finding also indicates that many of the dynamics that these models describe are barely understood and hard to represent by mathematical descriptions. Given the wide ranges that evolve already in 2030, one can imagine the uncertainty levels for 2050 or 2100 . One option to keep this long-term uncertainty manageable is to use different models for different time horizons (see also Ref. [88]). For longer term projections, different (i.e. simpler) models can be used that better describe the rough dynamics that take place over longer time periods. Options to improve this specific model, which might also decrease calibration uncertainty, are (1) to specify energy end-use functions, (2) to better account for hysteresis, and (3) explicitly account for regional energy policies. With respect to the first, more explicitly accounting for the heterogeneity in end-uses across world regions and adding intermediate variables like floor space and appliance ownership provides extra options for model calibration and explains much of the differences between regions (see Refs. [65,87]). Second, the model's incapability to deal adequately with declining economic activity, leads to nonbehavioural historic results and implicitly also unreliable future projections. The fact that future scenarios always assume increasing economic activity unveils another bias in energy use projections. Finally, specific policies, like protecting (poor) population from world energy prices, influence the use of energy in developing regions, an aspect that can be implemented in different scenarios see also Refs. [89].

\section{Acknowledgements}

The authors are grateful to Peter Janssen and Peter Heuberger for their contribution to the mathematical analysis and development of the MATLAB tool. This research is financially supported by the Netherlands Environmental Assessment Agency (PBL).

\section{Appendix 1. Values and ranges for parameter estimation}

Table 5

Ranges for the estimated parameters varied for residential fuel use.

\begin{tabular}{lll}
\hline Variable & Minimum & Maximum \\
\hline UEI-curve & & \\
$X_{\max }$ & 500 & 30000 \\
$Y_{0}$ & 0 & 0.159 (USA) 0.235 (EU) \\
& & 0.285 (Brazil) 0.284 (India) \\
U & & 0.285 (China) \\
AEEI & 15 & 45 \\
$F_{S}$ & & 0.68 (USA) 0.70 (EU) \\
& 0.09 (USA) 0.09 (EU) & 0.68 (Brazil) 1.0 (India) \\
PIEEI & 0.09 (Brazil) 0.07 (India) & 1.0 (China) $^{\mathrm{a}}$ \\
Payback time & 0.03 (China) & \\
P-value learning & 0.007 & 6.760 \\
$\quad$ curve & 0.70 & 1.00 \\
\hline
\end{tabular}

a Because of the high economic growth in India and China, it might be that historic $A E E I$ has been higher as well; therefore we increases the upped bound of the range to the total economic growth: $F_{S}=1$.

Table 6

Ranges for the estimated parameters varied for residential electricity use.

\begin{tabular}{lll}
\hline Variable & Minimum & Maximum \\
\hline UEI-curve & & \\
$X_{\max }$ & 5000 & 50000 \\
$Y_{0}$ & 0 & 0.141 (USA) 0.097 (EU) \\
& & 0.087 (Brazil) 0.039 (India) \\
$\mathrm{U}$ & & 0.068 (China) \\
AEEI & 50 & 80 \\
$F_{S}$ & & \\
& 0.09 (USA) 0.09 (EU) & 0.68 (USA) 0.70 (EU) \\
& 0.09 (Brazil) 0.07 (India) & 0.68 (Brazil) 1.0 (India) \\
PIEEI & 0.03 (China) & 1.0 (China) \\
Payback time & 0.007 & 6.760 \\
$P$-value learning & 0.70 & 1.00 \\
$\quad$ curve & & \\
\hline
\end{tabular}

a Because of the high economic growth in India and China, it might be that historic $A E E I$ has been higher as well; therefore we increases the upped bound of the range to the total economic growth: $F_{S}=1$.

Table 7

Average annual GDP per capita growth for the analysed regions.

\begin{tabular}{clllll}
\hline & USA & WEU & Brazil & India & China \\
\hline $\begin{array}{c}\text { Average annual GDP/cap } \\
\text { growth 1971-2003 }\end{array}$ & $2.19 \%$ & $2.13 \%$ & $2.21 \%$ & $2.69 \%$ & $6.69 \%$ \\
\hline
\end{tabular}




\section{Appendix 2. Calibrated parameter values}
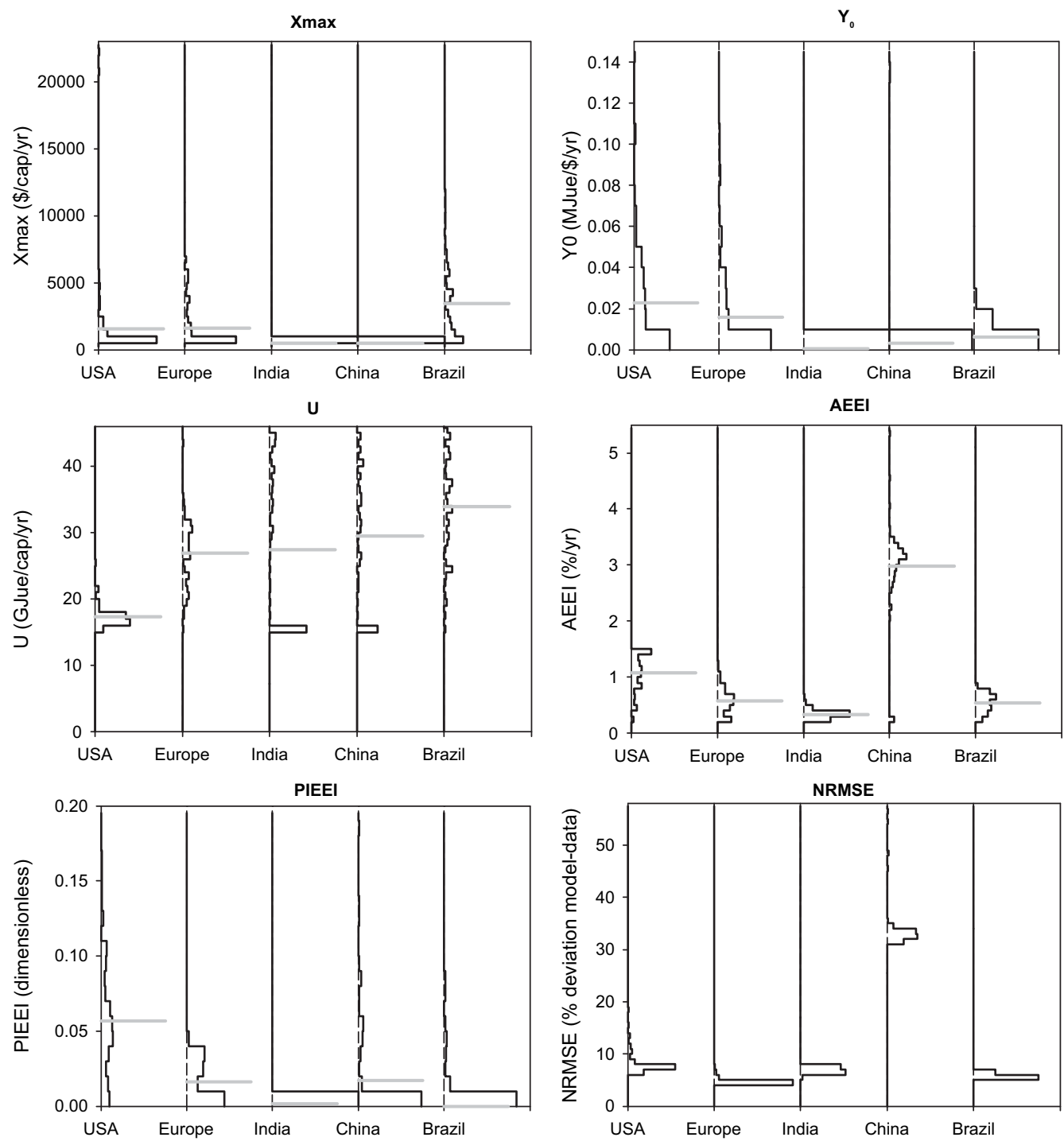

Fig. 6. Calibrated parameter values (distribution, black lines, and mean value, grey) for residential fuel use. 

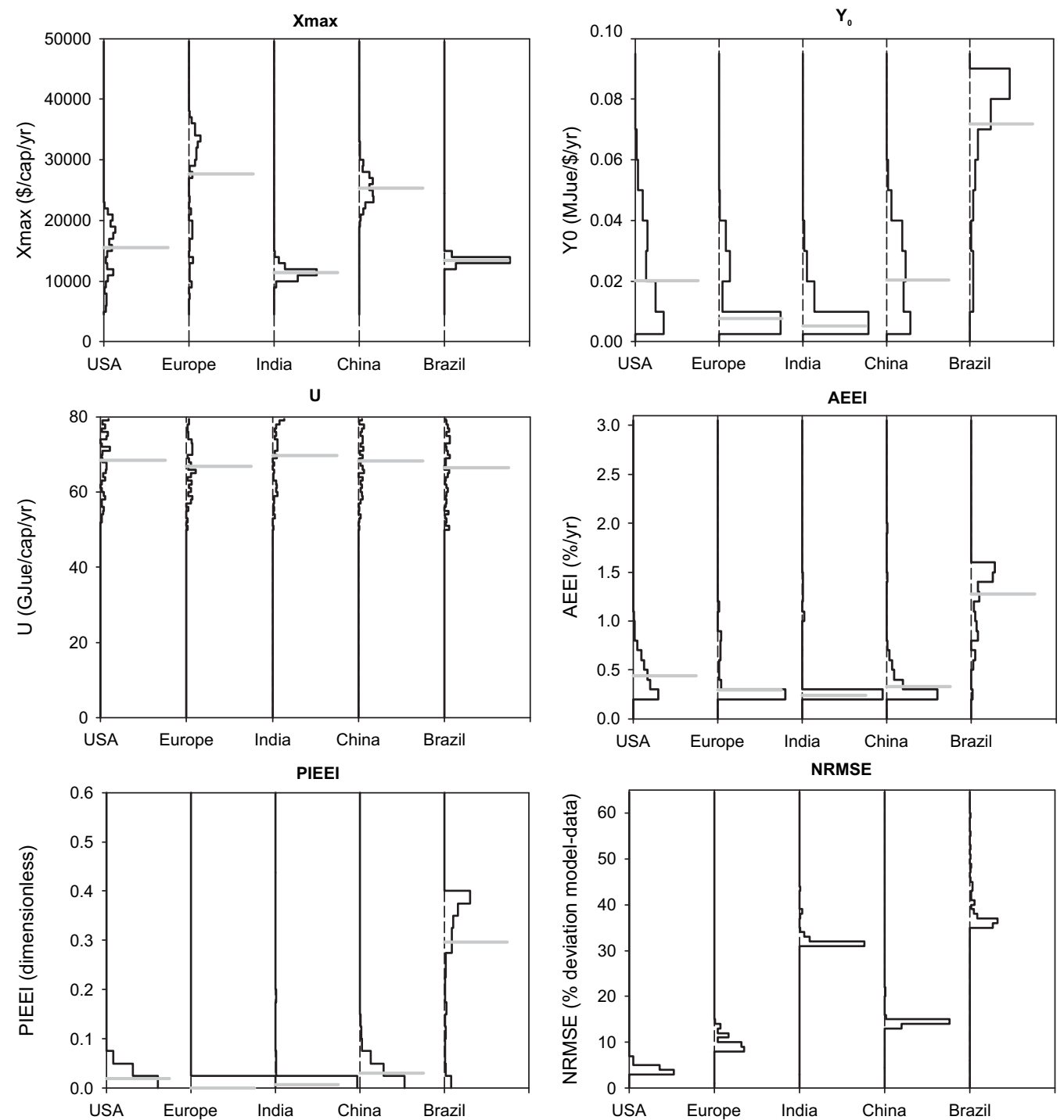

Fig. 7. Calibrated parameter values (distribution, black lines, and mean value, grey) for residential electricity use.

\section{References}

[1] Riahi K, Roehrl RA. Greenhouse gas emissions in a dynamics-as-usual scenario of economic and energy development. Technology Forecasting and Social Change 2000;63:175-205.

[2] Azar C, Lindgren K, Andersson BA. Global energy scenarios meeting stringent $\mathrm{CO}_{2}$ constraints - cost-effective fuel choices in the transportation sector. Energy Policy 2003;31:961-76.

[3] Criqui P, Kouvaritakis N. World energy projections to 2030. International Journal of Global Energy Issues 2000;14(1-4):116-36.

[4] de Vries HJM, van Vuuren DP, den Elzen MGJ, Janssen MA. The TIMER image energy regional (TIMER) model, 461502024/2001. Bilthoven: National Institute for Public Health and the Environment (RIVM); 2001.

[5] Turton H. ECLIPSE: an integrated energy-economy model for climate policy and scenario analysis. Energy 2008;33(12):1754-69.

[6] Loulou R, Goldstein G, Noble K. Documentation for the MARKAL family of models, ETSAP; 2004.

[7] Kainuma M, Matsuoka Y, Morita T, editors. Climate policy assessment, AsiaPacific integrated modeling. Tokyo: Springer-Verlag; 2003

[8] Syri S, Amann M, Capros P, Mantzos L, Cofala J, Klimont Z. Low- $\mathrm{CO}_{2}$ energy pathways and regional air pollution in Europe. Energy Policy 2001;29(11):871-84.

[9] Rana A, Shukla PR. Macroeconomic models for long-term energy and emissions in India. Opsearch 2001;38(1).

[10] Parikh KS, V Karandikar, A Rana, P Dani. Projecting India's energy requirements for policy formulation. Energy 2009; 34(8): 928-41.

[11] Manne A, Mendelsohn R, Richels R. MERGE: a model for evaluating regional and global effects of GHG reduction policies. Energy Policy 1995;23(1): 17-34.
[12] CPB. Worldscan: the core version. Den Haag: Netherlands Bureau for Economic Policy Analysis (CPB); 1999.

[13] Worrell E, Ramesohl S, Boyd G. Advances in energy forecasting models based on engineering economics*. Annual Review of Environment and Resources 2004;29(1):345.

[14] Shukla PR. Greenhouse gas models and abatement costs for developing nations: A critical assessment. Energy Policy 1995;23(8):677-87.

[15] van Vuuren DP, MM Hoogwijk, T Barker, K Riahi, S Boeters, J Chateau, et al. Comparison of methods for top-down and bottom-up estimates of sectoral and regional greenhouse gas emission reduction potentials. Energy Policy, in press.

[16] Kann A, Weyant J. Approaches for performing uncertainty analysis in largescale energy/economic policy models. Environmental Modeling and Assessment 2000;5(1):29-46.

[17] van der Sluijs JP, Potting J, Risbey J, van Vuuren D, de Vries B, Beusen A, et al. Uncertainty assessment of the IMAGE-TIMER B1 $\mathrm{CO}_{2}$ emissions scenario, using the NUSAP method, 410200104 (2002). Dutch National Research Program on Climate Change; 2001.

[18] van Vuuren DP, de Vries HJM, Beusen A, Heuberger PSC. Uncertainty ranges for the IPCC SRES scenarios: probabilistic estimates conditional on the storyline; 2007.

[19] Tschang FT, Dowlatabadi H. A Bayesian technique for refining the uncertainty in global energy model forecasts. International Journal of Forecasting 1995;11(1):43-61.

[20] van Ruijven BJ, JP van der Sluijs, DP van Vuuren, HJM de Vries, PHM Janssen, PSC Heuberger. Uncertainty from model calibration: applying a new method to calibrate energy demand for transport. Environmental Modeling \& Assessment, in press.

[21] Beven K. A manifesto for the equifinality thesis. Journal of Hydrology 2006;320(1-2):18-36. 
[22] van Vuuren, D.P., B.J. van Ruijven, M.M. Hoogwijk, M. Isaac, and H.J.M. de Vries. TIMER 2.0, model description and application. In: A.F. Bouwman, M.P.M. Hartman, and C.G.M. Klein Goldewijk, Editors. Integrated modelling of global environmental change. An overview of IMAGE 2.4. Bilthoven: Netherlands Environmental Assessment Agency (MNP); 2006.

[23] van Vuuren DP, de Vries B, Beusen A, Heuberger PSC. Conditional probabilistic estimates of 21 st century greenhouse gas emissions based on the storylines of the IPCC-SRES scenarios. Global Environmental Change 2008;18(4):635-54.

[24] Risbey J, Van der Sluijs JP, Kloprogge P, Ravetz J, Funtowicz S, Corral Quintana S. Application of a checklist for quality assistance in environmental modelling to an energy model. Environmental Modeling \& Assessment 2005;10(1):63-79.

[25] van der Sluijs JP. Uncertainty, assumptions, and value commitments in the knowledge-base of complex environmental problems. In: ÂG Pereira, SG Vaz, S Tognetti, ed. Interfaces between science and society: Green Leaf Publishing; 2006. p. 67-84.

[26] van der Sluijs JP. A way out of the credibility crisis of models used in integrated environmental assessment. Futures 2002;34(2):133-46.

[27] van der Sluijs JP. Uncertainty as a monster in the science policy interface: four coping strategies. Water Science and Technology 2005;52(6):87-92.

[28] van der Sluijs JP. Uncertainty and precaution in environmental management: insights from the UPEM conference. Environmental Modelling \& Software 2007;22(5):590-8.

[29] Refsgaard JC, van der Sluijs JP, Hojberg AL, Vanrolleghem PA. Uncertainty in the environmental modelling process - a framework and guidance. Environmental Modelling \& Software 2007;22(11):1543-56.

[30] Refsgaard JC, van der Sluijs JP, Brown J, van der Keur P. A framework for dealing with uncertainty due to model structure error. Advances in Water Resources 2006;29:1586-97.

[31] Kleindorfer GB, O'Neill L, Ganeshan R. Validation in simulation: various positions in the philosophy of science. Management Science 1998;44(8):1087-99.

[32] Oliva R. Model calibration as a testing strategy for system dynamics models. European Journal of Operational Research 2003;151(3):552-68.

[33] Barlas Y. Multiple tests for validation of system dynamics type of simulation models. European Journal of Operational Research 1989;42(1):59-87.

[34] Doherty J. PEST model-indipendent parameter estimation, user manual. 5th ed. Brisbane, Australia: Watermark Numerical Computing; 2004.

[35] Poeter EP, Hill MC, Banta ER, Mehl S, Christensen S. UCODE_2005 and six other computer codes for universal sensitivity analysis, calibration, and uncertainty evaluation. US Geological Survey 2005.

[36] Beven K, Binley A. The future of distributed models: model calibration and uncertainty prediction. Hydrological Processes 1992;6(3):279-98.

[37] Saltelli A, Tarantola S, Campolongo F, Ratto M. Sensitivity analysis in practice, a guide to assessing scientific models. Chichester: John Wiley \& Sons, Ltd.; 2004.

[38] Janssen PHM, Heuberger PSC. Calibration of process-oriented models. Ecological Modelling 1995;83(1-2):55-66.

[39] NIST/SEMATECH. e-handbook of statistical methods. Gaithersburg, USA: National Institute of Standards and Technology. Available at: http://www.itl. nist.gov/div898/handbook/; 2006.

[40] Mathworks. Optimization toolbox, user's guide. Natick, MA: USA; 2007.

[41] IPCC. Special report on emission scenarios. Cambridge: Intergovernmental Panel on Climate Change, Cambridge University Press; 2000.

[42] UNEP. Global environment outlook: environment for development. Nairobi: United Nations Environment Program; 2007.

[43] MA. Millenium ecosystem assessment: ecosystems for human wellbeing. Washington DC: Island Press; 2005.

[44] Medlock III KB, Soligo R. Economic development and end-use energy demand. Energy Journal 2001;22(2):77.

[45] Focacci A. Emperical analysis of the environmental and energy policies in some developing countries using widely employed macroeconomic indicators: the cases of Brazil, China and India. Energy Policy 2005;33:543-54.

[46] Reddy AKN, Goldemberg J. Energy for the developing world. Scientific American 1990;263(3):111.

[47] Stern DI. The rise and fall of the environmental Kuznets curve. World Development 2004;32(8):1419-39.

[48] van Ruijven B, Urban F, Benders RMJ, Moll HC, van der Sluijs JP, de Vries B, et al. Modeling energy and development: an evaluation of models and concepts. World Development 2008;36(12):2801-21.

[49] van Vuuren DP, Strengers BJ, De Vries HJM. Long-term perspectives on world metal use-a system-dynamics model. Resources Policy 1999;25(4):239-55.

[50] Kander A, Schon L. The energy-capital relation-Sweden 1870-2000. Structural Change and Economic Dynamics 2007;18(3):291-305.

[51] Gales B, Kander A, Malanima P, Rubio M. North versus south: energy transition and energy intensity in Europe over 200 years. European Review of Economic History 2007;11(2):219-53.

[52] Seppälä T, Haukioja T, Kaivo-oja J. The EKC hypothesis does not hold for direct material flows: environmental Kuznets curve hypothesis tests for direct material flows in five industrial countries. Population \& Environment 2001;23(2):217-38.

[53] Bernardini O, Galli R. Dematerialization: long-term trends in the intensity of use of materials and energy. Futures 1993;25(4):431-48.

[54] Groenenberg H. Development and convergence, a bottom-up analysis for the differentiation of future commitments under the climate convention. Utrecht: Universiteit Utrecht, Faculty of Chemistry; 2002.
[55] Agenor P-R, McDermott CJ, Prasad ES. Macroeconomic fluctuations in developing countries: some stylized facts. World Bank Economy Review 2000;14(2):251-85.

[56] Easterly W, Levine R. What have we learned from a decade of empirica research on growth? It's not factor accumulation: stylized facts and growth models. World Bank Economy Review 2001;15(2):177-219.

[57] AkInÇKose MA. Changing nature of north-south linkages: stylized facts and explanations. Journal of Asian Economics 2008;19(1):1-28.

[58] Mazzucato M, Semmler W. The determinants of stock price volatility: an industry study. Nonlinear Dynamics, Psychology, and Life Sciences 2002;6(2):197-216.

[59] Guillaume DM, Dacorogna MM, Davé RR, Müller UA, Olsen RB, Pictet OV. From the bird's eye to the microscope: a survey of new stylized facts of the intradaily foreign exchange markets. Finance and Stochastics 1997;1(2):95-129.

[60] Manne A, Richels R, Edmonds J. Market exchange rates or purchasing power parity: does the choice make a difference to the climate debate? Climatic Change 2005;71(1):1-8.

[61] IEA. Energy statistics of OECD member countries. Paris: International Energy Agency; 2008.

[62] Bank World. World development indicators (CD-ROM). World Bank; 2007.

63] IEA. Energy use in the new millennium - trends in the IEA countries. Paris: International Energy Agency; 2007.

[64] Schipper LJ, Haas R, Sheinbaum C. Recent trends in residential energy use in OECD countries and their impact on carbon dioxide emissions: a comparative analysis of the period 1973-1992. Mitigation and Adaptation Strategies for Global Change 1996;1(2):167-96.

[65] van Ruijven BJ. Energy and development - a modelling approach. Utrecht Utrecht University, Dept. of Science, Technology and Society, Faculty of Science; 2008.

[66] Lenzen M, Wier M, Cohen C, Hayami H, Pachauri S, Schaeffer R. A comparative multivariate analysis of household energy requirements in Australia, Brazil, Denmark, India and Japan. Energy 2006;31(2-3):181-207.

[67] IEA. Energy statistics of non-OECD countries. Paris: International Energy Agency; 2008.

[68] Brito J. Fuelwood utilization in Brazil. Biomass and Bioenergy 1997;12(1): 69-74.

[69] Goldemberg J, Mielnik O. Energy balance of Brazil. Energy for Sustainable Development 1996;II(6):7-10.

[70] Goldemberg J, Coelho ST, Rei F. Brazilian energy matrix and sustainable development. Energy for Sustainable Development 2002;VI(4):55-9.

[71] Schaeffer R, Szklo AS, Cima FM, Machado G. Indicators for sustainable energy development: Brazil's case study. Natural Resources Forum 2005;29: 284-97.

[72] Poole AD, de Hollanda JB, Tolmasquim MT. Energy conservation and greenhouse gas emissions in Brazil. Rio de Janeiro: INEE; 1998.

[73] McNeil MA, Letschert VE. Forecasting electricity demand in developing countries: a study of household income and appliance ownership. Berkeley, California: LBNL; 2007.

[74] Pachauri S. An energy analysis of household consumption - changing patterns of direct and indirect use in India. Dordrecht: Springer; 2007.

[75] NSSO. Housing condition in India, NSS report No. 489, 58th round (JulyDecember 2002). National Sample Survey Organisation, Dept. of Statistics, Govt. of India; 2003.

[76] Dzioubinski O, Chipman R. Trends in consumption and production: household energy consumption. New York: UN-DESA; 1999.

[77] IEA. Electricity in India - providing power for the millions. Paris: International Energy Agency; 2002.

78] Sinton JE, Smith KR, Peabody JW, Yaping L, Xiliang Z, Edwards R, et al. An assessment of programs to promote improved household stoves in China. Energy for Sustainable Development 2004; VIII(3):33-52.

[79] Brockett D, Fridley D, Lin J, Lin J. A tale of five cities: the China residential energy consumption survey. In: ACEEE summer study on building energy efficiency. Pacific Grove, California: ACEEE; 2002

[80] Sinton J, Fridley DG. Comments on recent energy statistics from China. Sinosphere 2003.

[81] van Vuuren DP, Fengqi Z, de Vries B, Kejun J, Graveland C, Yun L. Energy and emission scenarios for China in the 21st century-exploration of baseline development and mitigation options. Energy Policy 2003;31(4):369-87.

[82] Kram T, Bakkes J. Analysis of environmental pressures and impacts of the baseline for the second OECD environment outlook. Bilthoven: Netherlands Environmental Assessment Agency (MNP); 2006.

83] OECD. OECD environmental outlook to 2030. Paris: OECD; 2008.

[84] van Vuuren, D.P., M.G.J. Den Elzen, J. Van Vliet, T. Kram, P.L. Lucas, and M. Isaac. Comparison of different climate regimes: the impact of broadening participation. Submitted for publication. Energy Policy, in press.

[85] IEA. World energy outlook 2004. Paris: International Energy Agency; 2004.

[86] Doe-Eia. Annual energy review. Washington DC: US Department of Energy; 2006.

87] Isaac M, Van Vuuren DP. Modeling global energy use for heating and cooling in the residential sector in the context of climate change. Energy Policy 2008;37(2):507-21.

88] Casman EA, Morgan MG, Dowlatabadi H. Mixed levels of uncertainty in complex policy models. Risk Analysis 1999;19(1):33-42.

[89] van Vuuren DP. Energy systems and climate policy. Utrecht: Utrecht University, Dept. of Science, Technology and Society, Faculty of Science; 2007. 